\title{
Validation and Utility of the Meaning in Life Measure for Turkish University Students
}

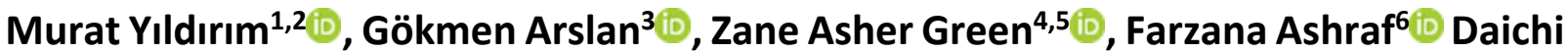 \\ Sugawara7 ${ }^{7}$, Ahmet $\operatorname{Tanhan}^{8,9}{ }^{(D)}$, Mehtap Asağlı ${ }^{10}$, Mai Helmy ${ }^{11,12}$, and Illhan Çiçek $^{13}$ (i)
}

\begin{abstract}
The Meaning in Life Measure (MILM) is a new measure for assessing meaning in life by addressing problems associated with existing measures of meaning in life (absence of items related to reflectivity, felt sense, and mattering). For the first time, this study aimed to test the psychometric properties of the MILM for university students in Turkey. We used a sample of 376 university students (Mage $=24.03 \pm 4.65$ years) who participated in an online survey including the MILM, the Adult Dispositional Hope Scale, and the Depression, Anxiety, and Stress Scale -21 . To study the factor structure of the MILM, we firstly employed a dual approach including exploratory and confirmatory factor analysis, which provided support for the goodness of a two-factor model (experience and reflectivity). We secondly tested the convergent and predictive validity of the measure by respectively applying correlation and regression analyses. Our findings supported the convergent validity of the MILM, showing correlations with hope, anxiety, and depression. The predictive validity was also confirmed; the experience subscale of MILM uniquely predicted hope, anxiety, and depression after controlling for covariates (age and gender). Thirdly, our findings showed that the MILM and its subscales had high internal consistency reliability. The Turkish version of the MILM is provided to be a reliable and valid instrument for assessing meaning in life for university students in Turkey.
\end{abstract}

Keywords: Meaning in Life Measure, psychometric properties, factor analyses, Turkish validation, well-being, mental health

Meaning in life is an essential ingredient of psychological well-being and mental health (Arslan \& Allen, 2021; Ryff \& Singer, 1996; Yıldırım et al., 2021). Viktor Frankl's Theory of Meaning proposes that life has a purpose and meaning, and that people have a tendency and desire to find meaning in their lives (Frankl, 2000). Acceptance and Commitment Therapy (ACT) being one of the most effective evidence-based therapies and thousand years old spiritual traditions give a unique space to meaning (Tanhan, 2019). The importance of meaning in life for the promotion of well-being and mental health have been frequently highlighted by theorist and researchers. Studies

\footnotetext{
${ }^{1}$ Department of Psychology, Ağrı İbrahim Çeçen University, Ağrı, Turkey

${ }^{2}$ Department of Neuroscience, Psychology and Behaviour, University of Leicester, Leicester, United Kingdom

${ }^{3}$ Department of Psychological Counseling and Guidance, Burdur Mehmet Akif Ersoy University, Burdur, Turkey

${ }^{4}$ Faculty of Business Administration, Preston University, Islamabad, Pakistan

${ }^{5}$ Contemporary Research Initiative, Preston University, Islamabad, Pakistan

${ }^{6}$ Department of Humanities, COMSATS University Islamabad, Lahore Campus, Pakistan

${ }^{7}$ Department of Human Sciences, University of Tsukuba, Tsukuba, Japan

${ }^{8}$ Department Counseling, The University of North Carolina at Greensboro, Greensboro, USA

${ }^{9}$ Department of Counseling, Adiyaman University, Adiyaman, Turkey

${ }^{10}$ Republic of Turkey Ministry of National Education, Ankara, Turkey

${ }^{11}$ Department of Psychology, Sultan Qaboos University, Muscat, Oman

${ }^{12}$ Department of Psychology, Menoufia University, Shebin El-Kom, Egypt

${ }^{13}$ Department of Child Development, Batman University, Batman, Turkey
}

Corresponding Author: Murat Yıldırım, Department of Psychology, Faculty of Science and Letters, Ağrı İbrahim Çeçen University, Erzurum Yolu 4 Km 04100, Merkez, Ağrı, Turkey

Email: muratyildirim@agri.edu.tr ; muratyildirimphd@gmail.com 
showed that meaning in life increases mental health-related outcomes such as happiness, positive emotions, wellbeing and coping strategies and reduces symptoms of stress, anxiety and depression (Arslan et al., 2020; Arslan \& Yıldırım, 2021; Hill et al. 2019; Yıldırım, 2020; Yıldırım \& Arslan, 2021). Meaning in life, for example, acts as a a protective factor for promoting well-being and mental health as it mitigates adversity (Arslan \& Y1ldırım, 2021). Furthermore, Ashraf et al. (2020) found that reduced meaning in life is increasing the risk of depression, anxiety, and loss of confidence. Moreover, studies using Online Photovoice (OPV) approach, which is an innovative, therapeutic, comprehensive, community-based, and phenomenological qualitative method that allows people to create their own themes, showed that approximately one in nine people reported searching for meaning to be the most important facilitator for their mental health during the difficult times (Tanhan, 2020, Tanhan et al., 2021). Therefore, it is crucial to measure meaning in life with reliable and valid measures.

Over the past decades, different tools assessing meaning in life have been constructed based on definitions of meaning in life in diverse directions (e.g., Arslan, 2020). Despite their usefulness in assessing meaning in life, these measures have been questioned due to various limitations corresponding with the measures. In general, meaning in life measures suffer from drawbacks, including cooperating meaning with a purpose (Hill et al., 2015), and possessing inconsistent and problematic factor solutions (McGregor \& Little, 1998). In addition, scales, subscales, or items on those have been confounded with other conceptually related, yet distinct constructs. Moreover, existing measures of meaning in life have neglected important aspects of meaning in life, such as experience and reflectivity (Hill et al., 2019). Since most measures used to assess meaning in life are self-reported based on subjective perceptions, the main focus of this study is to examine the psychometric properties of the Meaning in Life Measure (MILM), which is a recently introduced measure of meaning in life (Hill et al., 2019). However, due to newly presented into the relevant literature, evidence regarding its usefulness and efficacy for assessing meaning in life is limited. Therefore, the MILM has been introduced to address the important issues (reflectivity, felt sense, and mattering) ignored in earlier tools related to existing measures of meaning in life. The MILM considers meaning in life from a multidimensional aspect. The MILM uses specific items referring to the experience and reflectivity of meaning in life rather than focusing on general statements of meaning in life based on subjective perception. As experience and reflectivity are considered two essential ingredients of meaning in life, the MILM is assumed to deal with limitations found in extant measures of meaning in life.

The MILM can be widespread globally due to its ease of administration, scoring, and interpretation. The MILM has also been supported with empirical evidence. It is recommended to be used as a measure of meaning in life. The MILM comprises of two subscales: MILM-experience and MILM-reflectivity. Both subscales include an equal number of items (four items per subscale). Both subscales include an equal number of items (four items per subscale). In both subscales, items describe feelings about feeling sense, significance/ mattering, goals/ purpose, comprehensibility/ coherence, and reflection. These two components are assumed to describe experiences and reflections related to meaning in life.

To the best of our knowledge, the MILM has not yet been available in different cultures. Other than the original measure (Hill et al., 2019), some evidence regarding the factor structure of the measure has only been reported in Turkish culture by Yıldırım (2021). In that study, Yıldırım (2021) used a sample from the public ranging in age between 18 and 58 years. By using exploratory and confirmatory factor analyses, he reported that the MILM has a two-factor solution with high internal consistency reliability. Using MILM, Y1ldirım (2021) also reported that meaning in life was negatively related to loneliness and psychological distress and served as a mediator between loneliness and psychological distress in the face of adversity. However, as far as we are aware, there is no validation of the MILM for university students in Turkey. Therefore, there is a need to provide evidence about the measure's utility in various samples and settings to enhance its usefulness and capability for cross-cultural research outcomes.

Considering advantages of this measure, the aim of this study was to examine the psychometric properties of the MILM in Turkish university students. We were particularly interested in studying whether the factorial structure of the measure is replicated in different samples, evaluating the convergent and predictive validity with measures of hope, anxiety, and depression. We were also interested in presenting evidence regarding the measure's reliability, particularly by considering internal consistency reliability. 


\section{Method}

\section{Participants}

The sample consisted of 376 university students (Mage=24.03 years, SD=4.65) from state universities in Turkey. The participants were attending bachelor's degree courses (73\%), master's degree courses (21\%), or Ph.D. and other specialization courses $(6 \%)$. There were $75.8 \%$ females and $24.2 \%$ males. The majority of participants $(68.4 \%)$ stated that they were belonged to average socioeconomic status.

\section{Measures}

Meaning in Life Measure (Hill et al., 2019). The measure comprises eight self-reported items grouped into two subscales with four items per subscale: experience and reflectivity (see Appendix). Higher scores on each subscale refer to higher level of experience and reflectivity related to meaning in life. A seven-point response format $(1=$ strongly disagree; $7=$ strongly agree) was used to rate each item (e.g., I can make connections between events in my past and present). In this study, Cronbach's alpha coefficients were .86 for overall meaning in life, .80 for experience, and .84 for reflectivity.

Adult Dispositional Hope Scale (Snyder et al., 1991). The 12-item Adult Dispositional Hope Scale was used to assess the trait hope of the participants. The scale includes pathways and agency subscales. Four of the items (e.g., "There are lots of ways around any problem") are presented on the pathways and the other four items (e.g., "I energetically pursue my goals") are included in the agency. The remaining four items are filler items. A combination of pathways and agency scores provide a total hope score. The Turkish adaptation of the scale was performed by Tarhan and Bacanlı (2015). Participants were asked to answer each item on a four-point response format $(1=$ Definitely false; 8 = Definitely true). Cronbach's alpha coefficient was .90 in this study.

Depression Anxiety Stress Scale-2 I (DASS-2I; Lovibond \& Lovibond, 1995). The DASS-21 is a selfreport scale assessing three distinct constructs of psychological states: depression, anxiety, and stress. Each subscale includes seven items, and each item is rated on a scale ranging from 0 (did not apply to me at all) to 3 (applied to me very much or most of the time). Higher scores on each subscale respectively refer to increased symptoms of depression, anxiety, and stress. Only items referring to depression (e.g., I couldn't seem to experience any positive feeling at all) and anxiety (e.g., I was aware of dryness of my mouth) subscales were used in this study. Yildirim and his colleagues (2018) reported good evidence of the reliability and validity of this scale in Turkish. Cronbach's alpha coefficients were respectively .91 for anxiety and .83 for depression in this study.

\section{Procedure}

Translation and back-translation procedure (Brislin, 1970) was used to validate the MILM in Turkish. The MILM was firstly translated from English to Turkish by two bilingual academics. Another bilingual academic translated it back from Turkish to English. All bilingual academics were fluent in both languages. Subsequently, language equivalency was evaluated between the two forms. The measure was implemented following assurance of language clarity and consistency. A cross-sectional survey research design was used to recruit participants online. An invitation was sent to all participants inviting them to take part in the online survey on meaning in life and mental health. All participants provided their informed consent before participating. They were fully informed about the purpose of the study, and their rights before and after the involvement in the study. Participants were assured about the confidentiality and anonymity of responses. Participation in the study was entirely voluntary with no incentives. Ethical approval for this study was obtained from the Institutional Review Board.

\section{Data Analysis}

Exploratory factor analysis using principal axis factoring was employed to assess the construct validity of the MILM. Confirmatory factor analysis was used to confirm the factorial structure of the MILM. A minimum cut-off of 0.90 for the Tucker-Lewis Index (TLI) and comparative fit index (CFI) and a maximum cut-off of 0.08 for the standard root mean square residual (SRMR) and for the root mean square error of approximation (RMSEA) were viewed as indicative of good fit (Marsh et al., 2004). Pearson product-moment correlation was performed to provide evidence regarding convergent validity. Next, regression analysis was carried out to establish predictive validity. Cronbach's alpha was applied to compute internal consistency reliability. Data were analysed using SPSS and AMOS version 25 for Windows. 


\section{Results}

\section{Exploratory Factor Analysis}

The Kaiser-Meyer-Olkin measure of sampling adequacy (.866) and Bartlett's test of sphericity with values 1261.59 $(\mathrm{df}=28 ; p<.001)$ demonstrated the viability to conduct the factor analysis. Eigenvalue greater than one criterion suggested the extraction of two factor. The first factor (experience) accounted for $52.19 \%$ of the total variance with an eigen value of 4.18 and the second factor (reflectivity) explained $12.85 \%$ of the total variance with an eigenvalue of 1.03. The factor loadings were moderate to large (see Table 1).

Table I. Factor loadings for MILM

\begin{tabular}{cccc}
\multicolumn{2}{c}{ EFA } & & \multicolumn{2}{c}{ CFA } \\
\cline { 1 - 1 } & $\lambda-\mathrm{E}$ & $\lambda-\mathrm{R}$ & $\lambda-\mathrm{R}$ \\
\hline
\end{tabular}

Experience items

1. I will be remembered

2. I can make connections between events in my past and present

$\begin{array}{llll}.86 & - & .63 & - \\ .74 & - & .70 & - \\ .44 & - & .67 & - \\ .86 & - & .66 & -\end{array}$

4. I experience my life as meaningful

\section{Reflectivity items}

5. I think about what gives me meaning

6. Meaning in life is a topic I value

7. There are times in my life when I think about what it all means

$\begin{array}{llll}- & .59 & - & .79 \\ - & .58 & - & .82 \\ - & .92 & - & .73 \\ - & .97 & - & .58\end{array}$

8. I often reflect about issues related to meaning in life

Note. $\lambda$-E $=$ factor loadings for experience subscale; $\lambda-\mathrm{R}=$ factor loadings for reflectivity subscale.

\section{Confirmatory Factor Analysis}

CFA was carried out using maximum likelihood to study the two-factor solutions that emerged from EFA. The model's goodness of fit was assessed using several fit indices, including TLI, CFI, RMSEA, and SRMR. The results of CFA showed a slightly poor data-model fit $(\mathrm{RMSEA}=0.12, \mathrm{CFI}=0.92, \mathrm{TLI}=0.88$, and $\mathrm{SRMR}=.0540$ ). Following suggestion of modification indices, we covaried item number 7 and item 8 on reflectivity to improve the model fit and the results showed a reasonable fit $(\mathrm{RMSEA}=0.08, \mathrm{CFI}=0.96$, TLI $=0.96$, and SRMR $=.0404$ ). The standardised factor loadings ranged between .63 and .71 for experience, and .66 and .80 for reflectivity (see Table 1).

Table 2. Descriptive statistics and correlations among the variables

\begin{tabular}{|c|c|c|c|c|c|c|c|c|c|c|c|}
\hline \multirow[b]{2}{*}{ Variable } & \multicolumn{5}{|c|}{ Descriptive Statistics } & \multicolumn{6}{|c|}{ Correlations } \\
\hline & Mean & $S D$ & Skew & Kurt & $\alpha$ & 1. & 2. & 3. & 4. & 5. & 6. \\
\hline 1. Meaning in life & 44.35 & 8.42 & -1.40 & 2.50 & .86 & - & $.91^{* *}$ & $.91^{* *}$ & $.51^{* * *}$ & $-.20^{* *}$ & $-.18^{* *}$ \\
\hline 2. MILM-Experience & 21.73 & 4.65 & -1.16 & 1.37 & .80 & & - & $.64^{* *}$ & $.55^{* *}$ & $-.27^{* *}$ & $-.23^{* *}$ \\
\hline 3. MILM-Reflectivity & 22.61 & 4.66 & -1.56 & 2.88 & .84 & & & - & $.37^{* *}$ & -.09 & -.10 \\
\hline 4. Hope & 47.68 & 9.10 & -0.64 & 0.94 & .90 & & & & - & $-.35^{* *}$ & $-.32^{* *}$ \\
\hline 5. Anxiety & 6.79 & 4.58 & 0.58 & -0.40 & .91 & & & & & - & $.66^{* *}$ \\
\hline 6. Depression & 11.32 & 3.20 & -0.31 & 0.71 & .83 & & & & & & - \\
\hline
\end{tabular}

\section{Convergent Validity}

Pearson correlation was carried out to provide evidence regarding convergent validity. The results showed that meaning in life (total) was significantly positively correlated with its subscales (experience and reflectivity) and hope and significantly negatively correlated with anxiety and depression. The experience subscale was significantly positively correlated with reflectivity and hope and that significantly negatively correlated with anxiety and depression. Reflectivity was significantly positively correlated with hope but not significantly correlated with 
anxiety and depression. Hope was negatively correlated with anxiety and depression. All correlations were significant at the $p<0.01$ level and the size of correlation coefficients ranged from small to large (see Table 2).

\section{Predictive Validity}

Regression analysis was conducted to present evidence concerning the predictive validity of the MILM. In the regression analysis, hope, anxiety, and depression were considered as outcome variables and subscales of MILM (experience and reflectivity) were considered as independent variables. Age and gender were controlled for in this analysis. The results showed that experience significantly positively predicted hope $(\beta=.51, p<.001)$, anxiety $(\beta=$ $.30, p<.001)$, and depression $(\beta=-.24, p<.001)$. The amount of unique variance explained by experience in hope, anxiety, and depression were respectively $29 \%, 19 \%$, and $12 \%$. The results of regression analyses are presented in Table 3.

Table 3. A summary of regression analysis predicting hope, anxiety, and depression with meaning in life subscales as predictors

\begin{tabular}{|c|c|c|c|c|}
\hline \multirow[b]{2}{*}{ Predictor } & \multicolumn{4}{|c|}{ Hope } \\
\hline & $B$ & $\beta$ & $t$ & $p$ \\
\hline Step 1 & \multicolumn{4}{|c|}{$F(2,375)=5.01, R=.16, R^{2}=.03, p<0.01$} \\
\hline Age & .17 & .16 & 3.16 & .00 \\
\hline Gender & -.39 & -.02 & -0.36 & .72 \\
\hline Step 2 & \multicolumn{4}{|c|}{$F(4,375)=42.04, R=.56, R^{2}=.31, p<.01$} \\
\hline MILM-Experience & 1.00 & .51 & 9.01 & .00 \\
\hline \multirow[t]{2}{*}{ MILM-Reflectivity } & .09 & .04 & .79 & .43 \\
\hline & \multicolumn{4}{|c|}{ Anxiety } \\
\hline Step 1 & \multicolumn{4}{|c|}{$F(2,375)=28.03, R=.36, R^{2}=.13, p<.01$} \\
\hline Age & -.17 & -.17 & -.17 & -.17 \\
\hline Gender & -1.54 & -1.54 & -1.54 & -1.54 \\
\hline Step 2 & \multicolumn{4}{|c|}{$F(4,375)=21.76, R=.44, R^{2}=.19, p<0.01$} \\
\hline MILM-Experience & -.29 & -.29 & -.29 & -.29 \\
\hline \multirow[t]{2}{*}{ MILM-Reflectivity } & .09 & .09 & .09 & .09 \\
\hline & \multicolumn{4}{|c|}{ Depression } \\
\hline Step 1 & \multicolumn{4}{|c|}{$F(2,375)=14.85, R=.27, R^{2}=.08, p<.01$} \\
\hline Age & -.09 & & -.09 & -.09 \\
\hline Gender & -.89 & & -.89 & -.89 \\
\hline Step 2 & \multicolumn{4}{|c|}{$F(4,375)=12.21, R=.34, R^{2}=.12,, p<0.01$} \\
\hline MILM-Experience & -.16 & & -.16 & -.16 \\
\hline MILM-Reflectivity & .04 & & .04 & .04 \\
\hline
\end{tabular}

\section{Reliability}

The Cronbach alpha coefficients of the total MILM with eight items was .86. The Cronbach alpha coefficients for the subscales were .80 for experience and .84 for reflectivity. These results suggest that the overall measure and subscale of meaning in life had good internal consistency reliability.

\section{Discussion}

In this current study, we presented a Turkish version of the MILM with good psychometric properties of reliability and validity in a sample of college students in Turkey. A two-factorial model was tested to assess the factorial structure of the MILM. The results of EFA and CFA in the present study indicated that meaning in life includes two related but distinct factors (experience and reflectivity). The good data-model fit shows that the distribution of the items in two factors in the present study is held valid. While these results are in accordance with the original proposal of the measure (Hill et al., 2019), they do not support the tripartite model of meaning in life proposed by George and Park (2016), Heintzelman and King (2014) and Martela and Steger (2016) who suggests the inclusion of coherence, mattering, and purpose in the measurement and conceptualization of meaning in life.

In support of convergent and predictive validity, the results showed that overall meaning in life and experience of meaning in life shared a significant positive correlation with hope and a significant negative correlation with 
depression, and anxiety. Reflective meaning in life shared a significant positive correlation with hope. These suggests that individuals with a high level of meaning in life tend to report a high level of hope and low levels of depression and anxiety. These results were further supported by regression analysis that experience of meaning in life accounted a significant amount of variance in greater hope and lesser depression and anxiety. These results are consistent with those of previous studies showing positive relationships between meaning in life and positive indicators of subjective well-being and negative relationships between meaning in life and negative indicators of well-being and mental health (Hill et al. 2019; Tanhan, 2019; Y1ldırım, 2020; Y1ldırım \& Arslan, 2021).

The inclusion of reflectivity dimension in the measurement and conceptualization of meaning in life is an important contribution for the development of the knowledge related to meaning in life. However, we failed to provide support for the unique contribution of the reflective meaning in life in explaining well-being and mental health outcomes. Indeed, Hill et al. (2019) also reported a significant yet small correlation between reflective meaning in life and well-being and mental health indices. Future research should further examine this in different settings to offer empirical support for the reflective meaning. The internal consistency reliability estimates for the overall measure and its subscales were high, suggesting that items on the overall MILM and its subscales are intended to assess the relevant construct by performing coherently showing that items on the experience and reflective meaning are internally related with each other. These findings are consistent with those of reported in the previous studies (Hill et al., 2019; Y1lırım, 2021).

\section{Implications}

The results of the current study have several implications for research and practice. The present study presented initial evidence that the concept and the measure of meaning in life holds true in Turkish culture. The findings demonstrated that the Turkish version of MILM has high reliability and validity. This study also showed that meaning in life is uniquely important for well-being and mental health outcomes by increasing hope and reducing anxiety and depression symptoms. In light of these findings, there is a need to address well-being and mental health of students at the university level in terms of students' support services via group and individual counselling for promotion of their greater well-being and mental health in the form of meaning in life. Cultivating meaning in life at the university may facilitate students', school adjustment, healthy interpersonal relationship, and academic achievement. In addition, the validation of the Turkish version of the MILM will provide opportunities for crosscultural comparison of the meaning in life research outcomes. Furthermore, the validation of the MILM has potential to develop a better understanding of the differences and similarities in the way this construct is examined across different cultures and contexts. Moreover, presenting a valid and reliable instrument for assessing of the meaning in life in Turkey will enable researchers, educators, healthcare professionals, and policymakers to design, apply, and evaluate the impacts of interventions focusing on cultivating wellbeing and mental health.

\section{Limitations}

This study is not without limitations. One of the salient limitations is the difficulty of recruiting a national representative sample. We used a convenience sampling approach limiting the ability to generalize the findings, particularly considering Turkish's cultural diversity. Furthermore, conducting the survey online is restricted to the cultural background of the participants. Therefore, it is important to examine the psychometric properties of the measure in other populations such as rural residents. In addition, given that meaning in life substantially changes throughout life and that sense of meaning in life for young people may not be appropriate for middle or older adults, subsequent research should use a larger number of older people. Due to the implementation of the study, which was exclusively done online, younger and highly educated participants predominated in this study. Less educated people should also be taken into account in future studies. In this study, temporal stability and sensitivity to explore changes in the scores of MILM were not carried out. Therefore, test-performing retest comparisons in clinical and nonclinical populations are recommended to detect changes in the sense of meaning in life. Moreover, by using the MILM, comparison of meaning in life across various demographic factors (e.g., age, gender, socioeconomic status, and educational background) would be useful to establish the measure's utility. Similarly, studying cross-cultural invariance of the MILM will provide further evidence regarding better understanding of the cultural, demographic, and socioeconomic indicators of meaning in life.

This study tested the psychometric properties of the MILM in Turkish. The MILM comprises two sub-scales: experience and reflectivity. The measure has good psychometric properties and can be used to assess meaning in life. Furthermore, this study contributed to the knowledge on the factorial structure of the measure. The link between 
the measure and mental health outcomes has also been further advanced. To conclude, the MILM is a reliable and valid measure which can be utilized both in academic research and educational and clinical settings.

\section{Compliance with Ethical Standards}

\section{Ethical Standards}

All study procedures involving human participants followed institutional and/or national research committee ethical standards and the 1964 Helsinki declaration and its later amendments or comparable ethical standards.

\section{Declaration of Conflicting Interests}

The author(s) declared no potential conflicts of interest with respect to the research, authorship, and/or publication of this article.

\section{Funding}

The author(s) received no financial support for the research, authorship, and/or publication of this article.

\section{Data Availability}

The datasets generated during and/or analyzed during the current study are available from the corresponding author on reasonable request.

ORCID

Murat Yildırım@https://orcid.org/0000-0003-1089-1380

Gökmen Arslan 1 https://orcid.org/0000-0001-9427-1554

Zane Asher Green (i)https://orcid.org/0000-0002-3959-9167

Farzana Ashraf (iD https://orcid.org/0000-0003-0110-2618

Daichi Sugawara $@$ https://orcid.org/0000-0001-6533-3592

Ahmet Tanhan 1 https://orcid.org/ 0000-0002-4972-8591

İlhan Çiçek@https://orcid.org/0000-0003-0266-8656

Published Online: September 14, 2021

\section{References}

Arslan, G. \& Allen, K. (2021). Exploring the association between coronavirus stress, meaning in life, psychological flexibility, and subjective well-being. Psychology, Health \& Medicine. https://doi.org/10.1080/13548506.2021.1876892.

Arslan, G. \& Yıldırım, M. (2021). Coronavirus stress, meaningful living, optimism, and depressive symptoms: A study of moderated mediation model. Australian Journal of Psychology, 73(2), 113-124. Australian Journal of Psychology. https://doi.org/10.1080/00049530.2021.1882273

Arslan, G. (2020). Anlamlı Yaşam Ölçeğinin geliştirilmesi: Anlamlı yaşama ilişkin kısa ve etkili bir ölçme aracı [Development of the Meaningful Living Measure: A brief and effective measure of meaningful living]. Mehmet Akif Ersoy University Journal of Education Faculty, 56, 227-242. https://doi.org/10.21764/ maeuefd.773686

Arslan, G., Yıldırım, M., Karataş, Z., Kabasakal, Z., \& Kılınç, M. (2020). Meaningful living to promote complete mental health among university students in the context of the COVID-19 pandemic. International Journal of Mental Health and Addiction. https://doi.org/10.1007/s11469-020-00416-8

Ashraf, F., Zareen, G., Nusrat, A., Arif, A., \& Griffiths, M. D. (2021) Correlates of Psychological Distress Among Pakistani Adults During the COVID-19 Outbreak: Parallel and Serial Mediation Analyses. Frontiers in Psychology, 12:647821. http//doi: 10.3389/fpsyg.2021.647821

Brislin, R. W. (1970). Back-translation for cross-cultural research. Journal of Cross-Cultural Psychology, 1(3), 185216. https://doi.org/10.1177/135910457000100301

Frankl, V. E. (2000). Man's Search for Ultimate Meaning. New York, NY: Basic Books.

George, L. S., \& Park, C. L. (2016). Meaning in life as comprehension, purpose, and mattering: Toward integration and new research questions. Review of General Psychology, 20, 205-220. https://doi.org/10.1037/gpr0000077 
Heintzelman, S. J., \& King, L. A. (2014). Life is pretty meaningful. American Psychologist, 69, 561-574. https://doi.org/10.1037/a0035049

Hill, C. E., Kline, K. V., Miller, M., Marks, E., Pinto-Coelho, K., \& Zetzer, H. (2019). Development of the Meaning in Life measure. Counselling Psychology Quarterly, 32(2), 205-226. https://doi.org/10.1080/09515070.2018.1434483

Hill, P. L., Burrow, A. L., Sumner, R., \& Young, R. K. (2015). Life is pretty meaningful and/or purposeful? On conflations, contexts, and consequences. American Psychologist, 70, 574-575. https://doi.org/10.1037/a0039209

Lovibond, S.H. \& Lovibond, P.F., (1995). Manual for the Depression Anxiety Stress Scales, 2nd ed. Psychology Foundation, Sydney. https://doi.org/10.1037/t01004-000

Marsh, H. W., Hau, K. T., \& Wen, Z. (2004). In search of golden rules: Comment on hypothesis-testing approaches to setting cutoff values for fit indexes and dangers in overgeneralizing $\mathrm{Hu}$ and Bentler's (1999) findings. Structural Equation Modeling, 11(3), 320-341. https://doi.org/10.1207/s15328007sem1103_2

Martela, F., \& Steger, M. F. (2016). The three meanings of meaning in life: Distinguishing coherence, purpose, and significance. Journal of Positive Psychology, 11, 431-545. https://doi.org/10.1080/17439760.2015.1137623

McGregor, I., \& Little, B. R. (1998). Personal projects, happiness, and meaning: On doing well and being yourself. Journal of Personality and Social Psychology, 74, 494-512. https://doi.org/10.1037/0022-3514.74.2.494

Ryff, C. D., \& Singer, B. (1996). Psychological well-being: Meaning, measurement, and implications for psychotherapy research. Psychotherapy and psychosomatics, 65(1), 14-23. https://doi.org/10.1159/000289026

Snyder, C. $\quad$ R., Harris, C., Anderson, J. $\quad$ R., Holleran, S. $\quad$ H., Irving, L. $\quad$ M., Sigmon, S. T., Yoshinobu, L., Gibb, J., Langelle, C., \& Harney, P. (1991). The will and the ways: Development and validation of an individual-differences measure of hope. Journal of Personality and Social Psychology, 60(4), 570-585. https://doi.org/10.1037/0022-3514.60.4.570

Tanhan, A. (2019). Acceptance and commitment therapy with ecological systems theory:

Addressing Muslim mental health issues and wellbeing. Journal of Positive Psychology and Wellbeing, 3(2), 197219. https://doi.org/10.47602/jpsp.v3i2.172

Tanhan, A. (2020). COVID-19 sürecinde Online Seslifoto (OSF) yöntemiyle biyopsikososyal

manevi ve ekonomik meseleleri ve genel iyi oluş düzeyini ele almak: OSF’nin Türkçeye uyarlanması. [Utilizing Online Photovoice (OPV) methodology to address biopsychosocial spiritual economic issues and wellbeing during COVID-19: Adapting OPV to Turkish.] Turkish Studies, 15(4), 1029-1086. https://doi.org/10.7827/TurkishStudies.44451

Tanhan, A., Arslan, G., Yavuz, K. F., Young, J. S., Çiçek, İ., Akkurt, M. N., Ulus, İ. Ç.,

Görünmek, E. T., Demir, R., Kürker, F., Çelik, C., Akça, M. Ş., Ünverdi, B., Ertürk, H., \& Allen, K. (2021). A constructive understanding of mental health facilitators and barriers through Online Photovoice (OPV) during COVID-19. ESAM Ekonomik ve Sosyal Araştırmalar Dergisi. https://doi.org/10.13140/RG.2.2.15257.13921

Tarhan, S., \& Bacanl, H. (2015). Adaptation of dispositional hope scale into Turkish: Validity and reliability study. The Journal of Happiness \& Well-Being, 3(1), 1-14.

Y1ldirım, M. (2021). Loneliness and Psychological Distress: A Mediating Role of Meaning in Life during COVID19 Pandemic [Online First], IntechOpen, DOI: 10.5772/intechopen.97477. Available from: https://www.intechopen.com/online-first/76383

Yıldırım, M., \& Arslan, G. (2021). A Moderated mediation effect of stress-related growth and meaning in life in the association between coronavirus suffering and satisfaction with life: Development of the Stress-Related Growth Measure. Frontiers in psychology, 12, 648236. https://doi.org/10.3389/fpsyg.2021.648236

Yıldırım, M., Arslan, G., \& Ahmad Aziz, I. (2020). Why do people high in COVID-19 worry have more mental health disorders? The roles of resilience and meaning in life. Psychiatria Danubina, 32(3-4), 505-512. https://doi.org/10.24869/psyd.2020.505

Yıldırım, M., Arslan, G., \& Wong, P. (2020). Meaningful living, resilience, affective balance, and psychological health problems among Turkish young adults during coronavirus pandemic. Current Psychology. https://doi.org/10.1007/s12144-020-01244-8

Yildirim, A., Boysan, M., \& Kefeli, M.C. (2018). Psychometric properties of the Turkish version of the Depression Anxiety Stress Scale-21 (DASS-21). British Journal of Guidance \& Counselling, 46(5), 582-595. https://doi.org/10.1080/03069885.2018.1442558 


\section{Appendix}

\section{Yaşamda Anlam Ölçeği}

Lütfen bir an için hayatınızın sizin için önemli olduğunu hissettiren şeyleri düşünün. Aşağıdaki her bir cümleyi okuyunuz ve size en uygun cevabı işaretleyiniz

$$
\begin{aligned}
& 1=\text { Kesinlikle katılmiyorum } \\
& 2=\text { Kat1lmiyorum } \\
& 3=\text { Kismen katılmiyorum } \\
& 4=\text { Karasızım } \\
& 5=\text { Kismen katıliyorum } \\
& 6=\text { Kat1liyorum } \\
& 7=\text { Kesinlikle kat1lyorum }
\end{aligned}
$$

\begin{tabular}{|l|l|l|l|l|l|l|l|}
\hline 1. Hatırlanacağım. & 1 & 2 & 3 & 4 & 5 & 6 & 7 \\
\hline 2. Geçmiş ve bugünkü olaylar arasında bağlantı kurabilirim. & 1 & 2 & 3 & 4 & 5 & 6 & 7 \\
\hline 3. Yaşamımda başarmak istediğim şeyler var. & 1 & 2 & 3 & 4 & 5 & 6 & 7 \\
\hline 4. Hayatımı anlamlı bir şekilde yaşıyorum. & 1 & 2 & 3 & 4 & 5 & 6 & 7 \\
\hline 5. Bana neyin anlam kattığı ile ilgili düşünürüm. & 1 & 2 & 3 & 4 & 5 & 6 & 7 \\
\hline 6. Hayattın anlamı, değer verdiğim bir konudur. & 1 & 2 & 3 & 4 & 5 & 6 & 7 \\
\hline 7. Hayatımda, her şeyin anlamını sorguladığım zamanlar olur. & 1 & 2 & 3 & 4 & 5 & 6 & 7 \\
\hline 8. Sıklıkla hayatın anlamı ile ilgili konular hakkında düşünürüm. & 1 & 2 & 3 & 4 & 5 & 6 & 7 \\
\hline
\end{tabular}

Notlar: Ölçek iki alt boyuttan oluşur. 1, 2, 3 ve 4 numaralı maddeler Yaşamda Anlam-Deneyim Alt Ölçeği'dir; 5, 6, 7 ve 8 numaralı maddeler Yaşamda Anlam-Yansıtma Alt Ölçeği'dir. Ölçekte tersten kodlanan maddeler yoktur. Her bir alt boyut için ilgili maddeler toplanır ve toplam puan elde edilir. Ölçek puanı iki alt boyutun toplam puanıdır.

*Bu ölçeğin yazarları, yazarlara atıfta bulunmak kaydıyla ölçeğin sadece akademik amaçla kullanılmasına izin verir. 